Duncan's Multiple Range Test. The results are given by question as follows:

(1) ("How probable do you think it is that the student's statements are truthful?") The analysis indicated no main or interaction effect of either sex of perceiver or sex of other. Neither sex was seen as more truthful than the other and neither sex was more credulous. There was, however, a significant main effect of situation ( $F=21.46 ; \mathrm{df}=1 ; \mathrm{p}<.01)$. The statement given by the student accused of cheating was more plausible than that of the student accused of possession of marijuana.

(2) ("... your opinion of the character of a student who would engage in this behavior.....') There were no significant main or interaction effects in this analysis. Both sexes judged both sexes in both situations as equally reprehensible. All means are between 5.2 and 5.9. A rating of 5 on this scale indicates an impression of $\mathrm{O}$ that is "a little below average" (as compared to other college students) while 6 is "a poor impression." The finding of no sex differences is in opposition to the hypotheses, which predicted main effects for sex of $P$, interaction of Sex of $O$ by Situation, and second-order interaction of Sex of P by Sex of $O$ by Situation.

(3) ("How severe should the punishment be if the charge ... were proven?') Analysis of responses to this question indicated a significant main effect for sex of $P$ $(F=6.79 ; d f=1 ; p<.05)$ as well as a significant interaction of Sex of $P$ by Sex of $O(F=4.86 ; \mathrm{df}=1 ; \mathrm{p}<.05)$. Males were more lenient judges than females, advocating less severe punishment for misdemeanors they had rated equally as reprehensible as females rated them. The Duncan showed, however, that Ss of both sexes prescribed similar punishments for male offenders, and that females did not discriminate between the sexes in recommending punishment. The significant interaction was due to the lenience of male Ps toward female Os. On the punishment scale for cheating, the means indicated that the average male thought that males should be given an $F$ in the course, but females should only be obliged to withdraw from it without credit. For possessing marijuana, males thought males should receive a $\$ 50.00$ fine, but females should only be put on probation. No main or interaction effects of situation were found on the punishment question. This finding does not mean that recommended punishments were equally severe for both offenses, since different specific penalities were provided by the punishment scales for the respective offenses.

The hypothesis that females are more moralistic than males was thus negated by one of the relevant dependent variables and partially supported by the other. Females did not make harsher judgments of character than males, but they recommended more severe punishment for the same offenses. Since, however, males were equally as severe as females in judging males, it would be more correct to speak of selective male lenience than of greater female punitiveness. This finding, it may be noted, was obtained where young male Ps were judging their contemporaries. Whether they would be equally partial to much older or younger females (i.e., those to whom they would be less likely to be attracted) is a question not answered by the study. Klinger et al (1964) found that when young adult Ps judged older Os, greater lenience in judgments of reprehensibility was shown to same-sex Os. (Punishment was not studied.) It may be, therefore, that the finding of male lenience to female $O s$ is dependent upon the relative ages of $P$ and $O$.

The fact that the predicted Sex of $\mathrm{O}$ by Situation interaction was not found may be a function of the sophistication of these Ss. Less well educated judges might have been selectively more censorious toward females in the personal misconduct situation. Here, too, the age of these Ss, who are part of the generation supposedly most involved in a moral revolution, may be a factor. On the other hand, however, the failure to obtain the predicted sex differences may be due to the fact that the "personal misconduct" described was milder than it might have been. More extreme behavior (e.g., promiscuous sexual behavior, use of more powerful narcotics) might have been judged more reprehensible in a female.

\section{REFERENCES}

CRISSMAN, P. Temporal change and sexual difference in moral judgments. Journal of Social Psychology, 1942, 16, 29-38.

CUSUMANO, D. R. Information valence in impression formation. Unpublished doctoral dissertation, St. Louis University, 1968.

KLINGER, E., ALBAUM, A., \& HETHERINGTON, M. Factors influencing the severity of moral judgments. Journal of Social Psychology, 1964, 63, 319-326.

ROSENCRANTZ, P. S., \& CROCKETT, W. H. Some factors influencing the assimilation of disparate information in impression formation. Journal of Personality \& Social Psychology, $1965,2,397-402$.

SKAGGS, E. B. Sex differences in moral attitudes. Journal of Social Psychology, 1940, 11, 3-10.

\title{
Discrimination between nutriments by the human neonate'
}

\section{JUDITH DUBIGNON and DUGAL CAMPBELL, Queen's University, Kingston, Ont., Canada}

Sucking in new-born infants was compared when no liquid was delivered, and when milk or a 5\% dextrose solution was delivered. No order effects were found. The milk elicited longer sucking bursts and increased the total time spent sucking. It appears that infants aged $48-90 \mathrm{~h}$ can discriminate milk from dextrose and that taste is the most likely basis for the discrimination.

The aim of this study was to determine whether the newborn infant can discriminate the difference between dextrose solution and milk.

Eckstein (1927) reported differentiation of taste sensation in premature babies using the sucking response as a criterion. In particular, bitter solutions resulted in an inhibition of sucking. Jensen (1932) compared sucking reactions to a variety of fluids, with milk at $40 \mathrm{deg} C$ as a control condition. $\mathrm{He}$ found positive reactions (reduced frequency and amplitude of sucking) to salt solutions as early as the second day of life, but no differential reactions to glucose $6 \%$, sterile water, or acid milk. Kron, Stein, Goddard, \& Phoenix (1967) compared sucking behavior in two groups of full-term babies fed milk and corn syrup, respectively. They reported a greater number of sucks per minute for milk and concluded that "milk has a higher stimulus value for the newborn than $5 \%$ corn syrup."

In a recent study (Dubignon \& Campbell, 1968), differences were found between sucking during a milk feed and sucking for small amounts of dextrose. During a feed the babies sucked more slowly but spent more of the available time sucking and consequently gave a greater number of sucks than when a small amount $(0.5 \mathrm{cc})$ of dextrose $5 \%$ was delivered for every 10 th suck. It was not clear from these results whether differences in the amount or the quality of the fluids delivered were responsible for the differences in sucking behavior.

\section{SUBJECTS}

Twenty bottle-fed infants were seen on the third or fourth day of life (mean age $68.2 \mathrm{~h}$, range $48-90 \mathrm{~h}$ ). All were normal, full-term babies born of multiparous mothers. 
Table 1

Mean Sucking Scores under Dextrose and Milk Conditions

\begin{tabular}{lcccc}
\hline Measures & Dextrose & Milk & F & p $<~$ \\
\hline Suction count (in 90 seconds) & 82.6 & 90.0 & 13.69 & .005 \\
Expression count (in 90 seconds) & 82.8 & 89.0 & 10.11 & .01 \\
Suction Time (seconds) & 61.1 & 66.9 & 11.31 & .005 \\
Expression time (seconds) & 60.3 & 64.2 & 3.59 & .10 \\
Suction rate (per second) & 1.356 & 1.353 & --- & --- \\
Expression rate (per second) & 1.376 & 1.395 & --- & -- \\
Suction amplitude (mm pen deflection) & 11.12 & 11.11 & --- & --- \\
Expression amplitude (mm pen deflection) & 7.24 & 7.71 & --- & --- \\
Mean sucks per burst & 13.37 & 15.93 & 4.21 & .10 \\
Mean duration of bursts (seconds) & 9.83 & 11.96 & 4.90 & .05 \\
Mean rate per burst & 1.355 & 1.369 & --- & --- \\
Number of bursts & 7.10 & 6.50 & 1.88 & --- \\
\hline
\end{tabular}

\section{APPARATUS}

Sucking behavior was measured in the laboratory using a specially adapted nipple (Dubignon \& Campbell, 1968). Two components of sucking, suction (negative pressure generated in the mouth) and expression (positive pressure on the nipple), were recorded by a polygraph. Measured amounts of fluid were delivered by two syringes which could be attached to a small tube leading to the tip of the nipple. The fluids used were a 5\% dextrose solution and the standard nursery formula which consists of a skimmed evaporated milk made up to contain $11 \mathrm{cal} / \mathrm{oz}$. The temperature of both fluids was approximately $35 \mathrm{deg}$ C.

\section{PROCEDURE}

The babies were brought to the laboratory during the hour before a regularly scheduled feed. Diapers were changed, the baby was bundled in a carrying blanket and held by $E 1$ in the normal feeding position. E 1 was responsible for giving the baby the nipple and recording on the polygraph every 10th suck using a foot-controlled event marker. A second $\mathrm{E}$ timed the trials and delivered $0.5 \mathrm{cc}$ of the appropriate fluid through the nipple for every 10th suck.

The procedure called for an initial baseline trial of $2 \mathrm{~min}$ of nonnutritive sucking with no fluid delivered. Two babies who did not reach a criterion of 40 sucks in 2 min were excluded from the study. The baseline sucking scores were also used to assign babies to two matched-order groups for the experimental trials which followed $30 \mathrm{sec}$ later. These consisted of two $2-\mathrm{min}$ nutritive sucking trials with $0.5 \mathrm{cc}$ fluid delivered to every 10 th suck. The trials were separated by a 30 -sec rest period. For 10 of the babies dextrose was delivered on the first trial and milk on the second trial; for the other 10 babies the milk condition preceded the dextrose condition.

\section{SCORING AND ANALYSIS}

Sucking was scored for the last $90 \mathrm{sec}$ of baseline and experimental trials to avoid the initial burst of sucking at the start of each trial which is not typical of later steady sucking performance (cf. Balint, 1948).
Twelve measures of sucking from the experimental trials were analyzed: suction and expression count in $90 \mathrm{sec}$; time spent in suction and expression in $90 \mathrm{sec}$; suction and expression rates (count divided by time amplitudes (mean sucking pressures). The remaining four measures concerned characteristics of sucking bursts (defined as two or more sucks separated by an interval greater than $1 \mathrm{sec}$ ), and were scored from the suction records only. These measures were: number of bursts; mean duration of bursts; mean number of sucks per burst; and mean sucking rate per burst. Results were evaluated in mixed model analyses of variance with order groups and conditions as main effects.

The baseline nonnutritive sucking counts, times, rates, and amplitudes were compared for the two order groups to ensure that they were adequately matched.

\section{RESULTS}

There were no significant differences in the baseline nonnutritive sucking scores of the two order groups.

The order of milk and dextrose sucking conditions gave rise to no significant differences in sucking scores; nor was the Order by Conditions interaction significant in any of the analyses.

Table 1 shows the means for those measures of sucking which differed significantly in milk and dextrose conditions. It can be seen that when the babies were sucking for milk they gave a greater number of sucks than when sucking for dextrose. Time spent in suction was also higher during the milk condition; expression time varied in the same direction although the difference was not reliable $(p<.10)$. Sucking bursts were longer and the babies tended to give more sucks per burst $(p<.10)$ during the milk condition. There were no significant differences in sucking rates, sucking pressures, number of sucking bursts or mean sucking rate per burst associated with dextrose and milk conditions.

\section{DISCUSSION}

The results indicate that newborn infants can discriminate between dextrose solution spent sucking); suction and expression and milk. The babies did not change their sucking rate but spent more time sucking and sucked in longer bursts when milk was delivered; as a consequence, they gave a greater number of sucks for milk than for dextrose. This agrees with the report by Kron, Stein, Goddard, \& Phoenix (1967) of differences in the sucking scores of two groups of babies fed milk and corn syrup respectively.

The dextrose solution and milk formula differ in a number of ways: nutrient value, odor, viscosity, and taste. Dextrose 5\% contains $6 \mathrm{cal} / \mathrm{oz}$ as compared with $11 \mathrm{cal} / \mathrm{oz}$ for the milk formula. In a large sample of babies studied previously $(\mathrm{N}=102)$ no differences in volume intake over the first 4 days of life were found in two groups fed on formulas containing 6-13 cal $/ \mathrm{oz}$ and $20 \mathrm{cal} / \mathrm{oz}$, respectively, and, as a result, there were marked differences in calorific intake (Dubignon, Curtis, Campbell, \& Partington ${ }^{2}$ ). It therefore seems unlikely that the babies regulate their sucking behavior in accordance with calorific value of the fluids.

Differences in the odor of the fluids also seem an unlikely basis for the discrimination since in the present study the fluids were held in a sealed syringe and the first delivery of fluid occurred only after the baby had given 10 sucks on the nipple. It therefore seems most probable that the basis for the discrimination was taste (although differences in viscosity cannot be ruled out).

The babies were seen on the third or fourth day of life so that it is not known whether the "preference" for milk is present at birth or established after birth through the association of milk with hunger reduction.

\section{REFERENCES}

BALINT, M. Individual differences of behavior in early infancy, and an objective method for recording them: II. Results and conclusions. Journal of Genetic Psychology, 1948, 73, 57-79.

DUBIGNON, J., \& CAMPBELL, D. Sucking in the newborn in three conditions: Non-nutritive, nutritive and a feed. Joumal of Experimental Child Psychology, 1968, 6, 335-350.

ECKSTEIN, A. Zur Physiologie der Geschmacksemfindung und des Saugreflexes bei Sauglingen. Zeitschrift fur Kinderheilk., 1927, 45, 1-19.

JENSEN, K. Differential reactions in newborn infants. Genetic Psychology Monograph, 1932, 12, 367-476.

KRON, R. E., STEIN, M., GODDARD, K. E., \& PHOENIX, M. D. Effect of nutrient upon the sucking behavior of newborn infants. Psychosomatic Medicine, 1967, 29, 24-32.

$$
\text { NOTES }
$$

1. This work was supported by the Ontario Mental Health Foundation (Grant No. 16) and the Laidlaw Foundation.

2. Dubignon, J., Curtis, M., Campbell, D., \& Partington, M. W. The relation between laboratory measures of sucking, food intake and peri-natal factors during the newborn period. Unpublished data, 1969. 